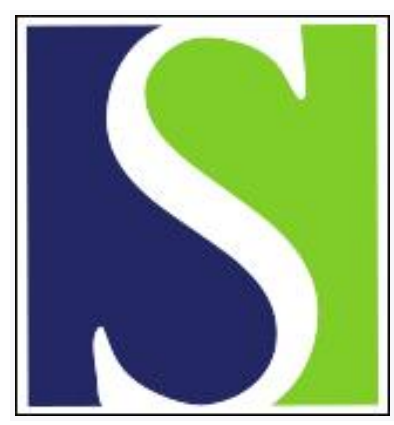

Scand J Work Environ Health 1989;15(1):38-42

https://doi.org/10.5271/sjweh.1884

Issue date: Feb 1989

\title{
Lung cancer, smoking, and employment in foundries.
}

by Becher H, Jedrychowski W, Flak E, Gomola K, Wahrendorf J

Affiliation: German Cancer Research Center, Institute of Epidemiology and Biometry, Heidelberg.

This article in PubMed: www.ncbi.nlm.nih.gov/pubmed/2922587 


\title{
Lung cancer, smoking, and employment in foundries
}

\author{
by Heiko Becher, PhD, ${ }^{1}$ Wieslaw Jedrychowski, MD, ${ }^{2}$ Elzbieta Flak, BSc, ${ }^{2}$ \\ Krystyna Gomola, BSc, ${ }^{2}$ Jürgen Wahrendorf, $\mathrm{PhD}^{1}$
}

\begin{abstract}
BECHER H, JEDRYCHOWSKI W, FLAK E, GOMOLA K, WAHRENDORF J. Lung cancer, smoking, and employment in foundries. Scand $J$ Work Environ Health 1989;15:38-42. A case-referent study on lung cancer was conducted in Cracow, Poland. Men dying of lung cancer within a 6-year period (1980-1985) formed the case group. The reference series was selected from death registers and was frequency-matched with the cases by sex and age. Deaths due to other respiratory diseases were excluded. Information on the occupation, smoking habits, and residency of 901 cases and 875 referents was collected from their next-of-kin. The combined effect of smoking and industrial exposure, in particular employment in steel or iron foundries, was investigated by multivariate analyses and was very well fitted by a multiplicative model. Foundry employment, in particular in the younger age $(<70$ years) group, occupational exposure to known carcinogens in other industries for more than 20 years, and smoking were found to be risk factors.
\end{abstract}

Key terms: attributable risk, case-referent study, foundry employment, lung neoplasm, relative risk.

While the use of tobacco products has been identified as a major causative factor for lung cancer (1), industrial and other environmental exposures are suspected to be contributors to the rising mortality from this disease. Chemical compounds which enter the ambient air from industrial processes may enhance the carcinogenicity of tobacco smoke in the lung. In recent years, it has become apparent that an excess in lung cancer risk might be associated with foundry exposures (2-4), although a relationship between exposure to specific pollutants in foundry air and an increased lung cancer risk has not yet been firmly established.

A pilot study carried out earlier (5) showed that the Cracow population, in comparison with all of Poland, had an excess of lung cancer deaths among men. Possible explanations include better reporting of deaths due to lung cancer in Cracow, a higher prevalence of smoking, or a greater degree of exposure to occupational hazards. The large case-referent study presented in this report aims at evaluating risk factors of lung cancer in a population with a high degree of exposure from occupations in the iron and steel industry while controlling for smoking and other factors. In addition, an attempt has been made to investigate interactive effects between foundry employment and cigarette smoke on lung cancer risk through the use of a thorough multivariate analysis.

\footnotetext{
${ }^{1}$ German Cancer Research Center, Institute of Epidemiology and Biometry, Heidelberg, Federal Republic of Germany.

2 Department of Epidemiology, Institute of Social Medicine, Medical School, Cracow, Poland.

Reprint requests to: Dr H Becher, German Cancer Research Center, Institute of Epidemiology and Biometry, Im Neuenheimer Feld 280, D-6900 Heidelberg, FRG.
}

\section{Subjects and methods}

All men whose death was attributed to primary lung cancer among male Cracow residents during 19801985 were identified from the death certificates. The men formed the case group. The referents were selected from the Cracow death register as the first person of the same sex and age ( \pm 5 years) entered with a cause of death other than respiratory cancer or chronic respiratory disease after each case. The death certificates obtained for the cases and referents were used to locate the next-of-kin for interview and hospital confirmation of the primary diagnosis.

A structured postal questionnaire was sent to 1273 next-of-kin of the cases and 1188 next-of-kin of the referents. If the questionnaire was not returned after one month, a reminder was sent, followed by a second one, if an answer was not received. The subjects from whom the questionnaires were not returned after three contacts were treated as nonrespondents. The response rate was $70.7 \%$ for the cases and $73.5 \%$ for the referents, ie, responses for 901 cases and 875 referents were received. The response rates were roughly similar across the age groups for both the cases and the referents. The data on the type of respondents showed that most of them were surviving spouses ( $60 \%$ for cases and $56 \%$ for referents) or offspring (31 and $30 \%$, respectively). Responses were missing for some of the questions.

Although the procedure of selecting the referents was linked to the cases on an individual basis for organizational purposes, this design was used only to provide sufficient frequency matching in respect to age and sex.

The questionnaire provided data on the decedent's residential, occupational, and smoking history, as well as demographic and other variables of interest. The occupational history covered the following items: 
branch of industry (eg, iron and steel industry, chemical industry) of longest held job, duration of work, job category (manual versus nonmanual), suspected exposure in job and its duration to coal, cement, asbestos dusts, metal dusts and fumes, or ionizing radiation. From these items a categorization into different occupational exposure groups was performed as follows: Workers from steel or iron foundries were divided into three exposure levels (exposure to one of the aforementioned substances for less than 20 years or an unknown duration, for 20 to 29 years, and for 30 years or more). Workers outside the steel industry who were exposed to the aforementioned substances for more than 20 years were treated as an "other exposure" category. The remaining group served as the nonexposed base-line category. This last category also included some individuals with missing information. The categorization into the exposure groups was based on information on the duration of exposure rather than on time at work in a specific industry because separate periods of work in nonhazardous places within the same factory could then be taken into consideration.

The data concerning smoking habits included the year the subject started smoking, the average number of cigarettes smoked daily, and the duration of smoking. From the smoking history data, the lifetime consumption of tobacco was estimated and expressed in pack-years. (One pack-year is equivalent to smoking 20 cigarettes daily for one year.) Accordingly, the following three groups were formed: $1-20$ pack-years, 20-40 pack-years, and more than 40 pack-years. Smokers with unknown lifetime consumption formed a separate group ("pack-years missing").

For the statistical analysis, logistic regression models (6) were fitted to the data with the SAS (statistical analysis system) software package for unconditional maximum likelihood estimation of the regression parameters. This analysis is appropriate for a frequency-matched design. All the variables but age were entered as categorical variables into the model. The factor age was taken into consideration in some models because the selection procedure for the referents, and a slightly higher response rate in the reference series in the older age groups, resulted in a slightly higher mean age for the reference group. The confidence intervals (CI) are given on the $95 \%$ level and are based on the normal approximation of the estimated regression coefficients. The attributable risks were computed according to a method suggested by Bruzzi et al (7).

\section{Results}

The age distribution of the cases and referents is shown for the entire groups and the foundry workers in the groups in table 1 . The mean age of the cases at death was 63.3 years, and that of the referents was 66.8 years. The next-of-kin of 106 cases $(12 \%)$ and 72 referents $(8 \%)$ reported the steel and iron industry as the usual employer of the deceased persons. The mean age of the persons having worked in this industry was 59.4 years for the cases and 64.0 years for the referents.

Table 2 gives the number of cases and referents in the exposure categories of the foundry workers and the corresponding numbers of those exposed in other industries or transport (truck drivers) for at least 20 years, and of those unexposed. Individuals below 70 years of age at death were considered separately and therefore their exposure experience is also given.

In table 3 the frequency distribution of the cases and referents is presented for the different occupational categories. Foundry workers formed the biggest sub-

Table 1. Age distribution of the cases and referents.

\begin{tabular}{|c|c|c|c|c|c|c|c|c|}
\hline \multirow{3}{*}{$\begin{array}{l}\text { Age group } \\
\text { (years) }\end{array}$} & \multicolumn{4}{|c|}{ Cases } & \multicolumn{4}{|c|}{ Referents } \\
\hline & \multicolumn{2}{|c|}{$\begin{array}{l}\text { Foundry } \\
\text { workers }\end{array}$} & \multicolumn{2}{|c|}{ Total } & \multicolumn{2}{|c|}{$\begin{array}{l}\text { Foundry } \\
\text { workers }\end{array}$} & \multicolumn{2}{|c|}{ Total } \\
\hline & $\mathrm{N}$ & $\%$ & $N$ & $\%$ & $N$ & $\%$ & $N$ & $\%$ \\
\hline $\begin{array}{r}<40 \\
40-49 \\
50-59 \\
60-69 \\
70-79 \\
>79\end{array}$ & $\begin{array}{r}- \\
14 \\
38 \\
39 \\
12 \\
3\end{array}$ & $\begin{array}{r}13.2 \\
36.8 \\
36.8 \\
11.3 \\
4.9\end{array}$ & $\begin{array}{r}12 \\
70 \\
254 \\
288 \\
235 \\
42\end{array}$ & $\begin{array}{r}1.3 \\
7.8 \\
28.2 \\
36.8 \\
26.1 \\
7.3\end{array}$ & $\begin{array}{r}4 \\
5 \\
18 \\
16 \\
23 \\
6\end{array}$ & $\begin{array}{r}5.6 \\
6.9 \\
25.0 \\
22.2 \\
32.0 \\
8.3\end{array}$ & $\begin{array}{r}20 \\
60 \\
164 \\
222 \\
283 \\
126\end{array}$ & $\begin{array}{r}2.3 \\
6.9 \\
18.7 \\
25.4 \\
32.3 \\
14.4\end{array}$ \\
\hline Total & 106 & 100 & 901 & 100 & 72 & 100 & 875 & 100 \\
\hline
\end{tabular}

Table 2. Number of workers in the occupational exposure.

\begin{tabular}{|c|c|c|c|c|c|c|c|}
\hline \multirow[b]{3}{*}{ Cases } & \multirow{2}{*}{$\begin{array}{c}\text { No } \\
\text { exposure }\end{array}$} & \multicolumn{4}{|c|}{ Foundry exposure (years) } & \multirow{2}{*}{$\begin{array}{c}\text { Other } \\
\text { exposurea } \\
\text { (>20 years) }\end{array}$} & \multirow{2}{*}{ Total } \\
\hline & & $<20$ & $20-29$ & $>30$ & Unknown & & \\
\hline & & & & & & & \\
\hline $\begin{array}{l}\text { Age }<70 \\
\text { years } \\
\text { Total }\end{array}$ & $\begin{array}{l}356 \\
535\end{array}$ & $\begin{array}{l}20 \\
29\end{array}$ & $\begin{array}{l}41 \\
45\end{array}$ & $\begin{array}{l}28 \\
29\end{array}$ & $\begin{array}{l}2 \\
3\end{array}$ & $\begin{array}{l}177 \\
260\end{array}$ & $\begin{array}{l}624 \\
901\end{array}$ \\
\hline \multicolumn{8}{|l|}{ Referents } \\
\hline $\begin{array}{l}\text { Age }<70 \\
\text { years } \\
\text { Total }\end{array}$ & $\begin{array}{l}353 \\
652\end{array}$ & $\begin{array}{l}17 \\
31\end{array}$ & $\begin{array}{l}16 \\
26\end{array}$ & $\begin{array}{r}8 \\
13\end{array}$ & $\begin{array}{l}2 \\
2\end{array}$ & $\begin{array}{r}70 \\
151\end{array}$ & $\begin{array}{l}466 \\
875\end{array}$ \\
\hline
\end{tabular}

a Exposure in other industries or transport.

Table 3. Branch of industry reported for the exposed workers by case or reference status.

\begin{tabular}{lrc}
\hline Branch of industry & $\begin{array}{c}\text { Cases } \\
(\mathrm{N})\end{array}$ & $\begin{array}{c}\text { Referents } \\
(\mathrm{N})\end{array}$ \\
\hline Steel of iron foundry & 106 & 72 \\
Engine construction & 23 & 12 \\
Chemical industry & 16 & 10 \\
Brick manufacturing and & 14 & 5 \\
cement industry & 2 & 1 \\
Ceramics & 19 & 12 \\
Building trade & 65 & 48 \\
Other industries & 35 & 18 \\
Transport services & & \\
(transportation) & 86 & 45 \\
Unknown & 366 & 223 \\
\hline Total & & \\
\hline
\end{tabular}


Table 4. Simultaneous relative risk (RR) estimates for the total group adjusted for age and based on a logistic regression analysis. ( $95 \% \mathrm{Cl}=95 \%$ confidence interval)

\begin{tabular}{|c|c|c|c|c|}
\hline & \multicolumn{2}{|c|}{ Total group ${ }^{a}$} & \multicolumn{2}{|c|}{ Age $<70$ years ${ }^{b}$} \\
\hline & $\mathrm{RR}$ & $95 \% \mathrm{Cl}$ & $R R$ & $95 \% \mathrm{Cl}$ \\
\hline \multicolumn{5}{|l|}{ Foundry } \\
\hline $\begin{array}{l}1-20 \text { years or unknown duration } \\
20-30 \text { years } \\
>30 \text { years }\end{array}$ & $\begin{array}{l}1.28 \\
1.58 \\
2.66\end{array}$ & $\begin{array}{l}0.75-2.20^{*} \\
0.94-2.66 \\
1.31-5.42\end{array}$ & $\begin{array}{l}1.51 \\
2.33 \\
3.99\end{array}$ & $\begin{array}{l}0.77-3.00^{* *} \\
1.26-4.32 \\
1.71-9.34\end{array}$ \\
\hline $\begin{array}{l}\text { Exposure }>20 \text { years in other } \\
\text { occupations }\end{array}$ & 1.76 & $1.37-2.25$ & 2.20 & $1.57-3.05$ \\
\hline \multicolumn{5}{|l|}{ Smoking (pack-years) ${ }^{c}$} \\
\hline $\begin{array}{l}1-20 \\
20-40 \\
>40\end{array}$ & $\begin{array}{l}1.38 \\
4.22 \\
6.40\end{array}$ & $\begin{array}{l}0.85-2.24^{* *} \\
2.90-6.14 \\
4.45-9.25\end{array}$ & $\begin{array}{l}1.64 \\
5.09 \\
8.00\end{array}$ & $\begin{array}{l}0.85-3.14^{* *} \\
2.99-8.68 \\
4.72-13.54\end{array}$ \\
\hline Pack-years missing & 3.13 & $1.93-5.07$ & 3.15 & $1.57-6.33$ \\
\hline Age at start of smoking $<18$ years & 1.25 & $1.00-1.66$ & . & . \\
\hline
\end{tabular}

a 901 cases and 875 referents.

b 624 cases and 466 referents.

c One pack-year $=$ smoking of 20 cigarettes daily for one year.

${ }^{\star} P=0.002,{ }^{\star}{ }^{\star} P<0.001\left(\chi^{2}\right.$ trend $)$.

group, but other frequently reported industries were machine construction, the chemical industry, and the building trade.

Table 4 shows the relative risk (RR) estimates derived from the final logistic model as the antilog of the regression parameters. The relative risk estimates were excessive for the foundry workers in all the exposure categories, and they showed an increasing trend with duration of exposure. The highest relative risk (RR 2.66) was determined for the highest exposure category $(95 \%$ CI $1.31-5.42)$. The test of linear trend appeared to be highly significant $(P=0.002)$. The category "exposure in other industries" also showed a significantly increased relative risk (RR $1.76,95 \% \mathrm{CI}$ $1.37-2.25$ ). Among the foundry workers three cases and two referents had missing data on duration of exposure. If considered separately, the estimated relative risk of this group was $2.2(95 \% \mathrm{Cl} 0.25-19.4)$. In the final model these individuals have been added to the lowest exposure group.

As expected, tobacco smoking was found to be the strongest risk factor. The estimated relative risks given in table 4 were found to increase with the amount of cigarette consumption. In the final logistic regression models the factor "age at start of smoking $<18$ years" was also introduced, as it showed an additional significant effect (RR 1.25, $95 \%$ CI 1.00-2.66).

In order to assess whether the relative risk patterns were more pronounced in the younger age group, we performed an additional analysis for the subgroup of individuals under 70 years of age. The ranges of the relative risk estimates for smoking were similar to those of the total group, but the age at the start of smoking had no effect in this subgroup. The risks for the foundry workers were considerably higher in the younger age group (table 4). The relative risk estimate for the middle exposure category (exposure 20-30 years) reached significance ( $R R 2.33,95 \%$ CI 1.26-4.32), and for the highest exposure group a fourfold lung cancer risk was observed (RR 3.99, $95 \%$ CI 1.719.34). The test for linear trend was highly significant $(\mathrm{P}<0.001)$.

With the purpose of examining a possible bias arising from the different sources of death certificate diagnosis (hospital versus doctors outside hospitals) and from the various types of informants, we used a variety of additional logistic models. Two different models were constructed - one for the hospital-deceased cases and another for the hospital cases that underwent postmortem medical examination. Despite a much smaller number of cases in these two additional models, the general risk pattern for lung cancer remained stable. In all three models the odds ratio estimates for the effects of smoking and occupational exposure appeared to be similar and significant. There were only small differences in the absolute values of the estimated relative risks.

In an attempt to elucidate a possible role of information bias, another model was constituted in which the source of "respondent" was controlled for (spouses versus others). No effect of type of respondent on the relative risk pattern was found. In order to look for other possible factors that may confound the results, we included two other variables in the model [educational level and place of birth (rural versus urban)] but neither improved the fit.

We also evaluated the possible interactive effects between smoking and occupational exposure among the foundry workers by adding the interaction terms into the final logistic model. The estimates were close to zero and hence indicated that the two factors act multiplicatively. The probability of foundry workers in the highest exposure category also being heavy smokers was estimated to be 32 -fold $(8.00 \times 3.99)$ that of the unexposed nonsmokers.

On the assumption of a joint distribution of smoking and long-term employment in the steel industry the 
population attributable risk estimates for Cracow were as follows: $72.3 \%$ for smoking, $2.5 \%$ for foundry employment, and $75.2 \%$ for all factors, including other occupational exposures for the total male population. For the male population under 70 years of age the corresponding numbers were $75.1,4.8$, and $78.0 \%$ respectively. Thus a higher proportion of lung cancer cases in the younger age group may be attributed to either of the risk factors.

\section{Discussion}

The main purpose of our study was the assessment of the effect of the occupational hazards due to employment in steel and iron foundries. It is necessary to mention that, in Cracow, a metallurgical complex was set up in 1955. In this complex the occupational hazards have not changed substantially over time. In our data we found that, after controlling for age and smoking habits (pack-years and age at the start of smoking), the suspected occupational exposure in the metallurgical industry affected the risk of lung cancer among men significantly. Its effects became more evident after long-term employment, ie, 30 years or more, and were more pronounced in the age group under 70 years. These findings may be explained by a reduction in risk after the cessation of employment or by an increasing misclassification of exposure information among older respondents. However, in this study, occupational history was not obtained in detail, and thus the time since last exposure could not be taken into consideration. Therefore, a younger aged subgroup was formed, as it may be assumed that the time since last occupational exposure was relatively short in this group and a reduction in lung cancer risk may not yet have taken place. The results were in agreement with the observations of Egan-Baum et al (8) who found an odds ratio of 2.36 for iron foundry workers who died before the age of 65 years and an odds ratio of only 1.19 for those who died after this age.

In this study no detailed occupational histories could be obtained, and no attempt was even made to identify specific carcinogenic agents. Instead we proposed to assess the magnitude of risks attributable to occupation in the iron and steel industry in general. Socioeconomic status has been known to be a major determinant of lung cancer, but, in this study, it had no independent effect after the exposure variable was included in the model. Although there are other industries which may involve exposures to the same range of putative carcinogens, the foundry workers formed the largest group, and a detailed analysis of the other groups did not seem feasible. Of some concern was the group of subjects who were reported to have occupational exposure but whose information on the branch of industry was missing. When the relative risk of this group was estimated separately, a value of 2.53 , consistent with that of the remaining group, was found.
This case-referent study in Cracow confirmed an increased risk of lung cancer previously reported among steel workers. Blot et al (9) found a significantly increased risk associated with employment in the steel industry. Adjusted for cigarette smoking, the odds ratio associated with career employment was $1.8(95 \%$ CI 1.2-2.8). For a subgroup of foundry workers the estimated relative risk was higher, but it was based on very small numbers.

Work in iron and steel foundries has been also linked to lung cancer in studies from several countries $(2,4$, $8,10-12)$. In these studies, the increased risk tended also to be the most pronounced among workers with the longest duration of employment. However, the responsible agent has yet to be identified. Many foundry processes give rise to various fumes or dusts. These emissions tend to be a very complex mixture of particles, chemicals, and gases, and their chemical and physical characteristics vary with the process from which they arise. Pyrolysis products include polycyclic aromatic hydrocarbons, some of which are known as carcinogens, and airborne particulates may be composed of metals or metal oxides, silica, carbon, or organic matter. Polynuclear hydrocarbons, which occur not only in foundries and near coke ovens, but also in industrial operations involving the conversion of iron to steel, are particularly suspect.

Of some concern in this type of study is the nextof-kin's ability to provide accurate information about the study subjects (13-19). Lerchen \& Samet (20) assessed the validity of surviving wives as a source of information on occupational exposure of their husbands by comparing the histories reported by the wives with those provided earlier by their husbands. Agreement for the usual job, ie, the job held the longest time, was $84 \%$ for the industries and $78 \%$ for the occupations. There was perfect agreement for cigarette smoking status (ever, never); however, wives tended to report 20 cigarettes smoked per day even when their husbands smoked substantially more or less. Pickle et al (21) evaluated the ability of several types of surrogate respondents to provide information on smoking, occupational, medical, and demographic characteristics. Spouses and offspring provided the most accurate information for events that occurred during adult life. Rogot \& Reid (22) compared self-reported occupations by British and Norwegian migrants to the United States with responses provided after their deaths by nextof-kin. In a classification scheme that included five broad occupational groups, agreement was $77 \%$.

In this study the rate of blank responses for various questions ranged from almost $0 \%$ up to $34 \%$. The response rates generally decreased with the amount of details requested and tended to be higher for those subjects over 70 years of age, particularly for questions on educational level and employment. Additional control for type of respondent (spouse versus others) did not result in substantial changes in the regression parameters. We think, however, that missing responses 
for these questions are more likely to signify "not applicable" than "don't know" and that an assignment into the "unexposed" category is therefore appropriate.

In summary, we conclude that long-term employment in the steel or iron foundry industry substantially increases the risk of lung cancer. Tobacco smoking, however, remains the dominant cause due to both higher relative risks and higher prevalence.

\section{Acknowledgments}

The useful comments and bibliographic help of Ms $U$ Lilje, as well as the secretarial assistance of Ms $\mathrm{H}$ Weis, are gratefully acknowledged.

The field study was supported by a grant from the Cancer Research Program coordinated by the Institute of Lung Diseases in Warsaw, Poland. The analysis of the data was financially supported by the German Cancer Research Center, Heidelberg, Federal Republic of Germany.

\section{References}

1. International Agency for Research on Cancer. Tobacco smoking. Lyon: International Agency for Research on Cancer, 1986. (IARC monographs on the evaluation of the carcinogenic risk of chemicals to humans; vol 38.)

2. Fletcher AC, Ades A. Lung cancer mortality in a cohort of English foundry workers. Scand J Work Environ Health 1984;10:7-16.

3. Palmer WG, Scott WD. Lung cancer in ferrous foundry workers: a review. Am Ind Hyg Assoc J 1981; 42:329-40.

4. Silverstein M, Maizlish N, Park R, Silverstein B, Brodsky L, Mirer F. Mortality among ferrous foundry workers. Am J Ind Med 1986;10:27-43.

5. Jedrychowski W, Szal H, Cholewka-Cabaj K. Monitoring of lung cancer death among inhabitants in Cracow [in Polish]. Przeg Lek 1984;41:309-14.

6. Breslow NE, Day NE. Statistical methods in cancer research; vol I (The analysis of case-control studies). Lyon: International Agency for Research on Cancer, 1980. (IARC scientific publications; no 32.)

7. Bruzzi P, Green SB, Byar DP, Brinton LA, Schairer C.
Estimating the attributable risk for multiple risk factors using case-control data. Am J Epidemiol 1985;122: 904-14.

8. Egan-Baum E, Miller BA, Waxweiler RJ. Lung cancer and other mortality patterns among foundrymen. Scand J Work Environ Health 1981;7 (suppl 4):147-55.

9. Blot WJ, Brown LM, Pottern LM, Stone BJ, Fraumeni JF. Lung cancer among long-term steel workers. Am J Epidemiol 1983;117:706-16.

10. Damber LA, Larsson LG. Occupation and male lung cancer: a case-control study in northern Sweden. Br J Ind Med 1987;44:446-53.

11. Koskela RS, Hernberg S, Kärävä R, Järvinen E, Nurminen M. A mortality study of foundry workers. Scand J Work Environ Health 1976;2 (suppl 1):73-89.

12. Lloyd JW. Long-term mortality study of steelworkers: $\mathrm{V}$ Respiratory cancer in coke plant workers. J Occup Med 1971;13:53-68.

13. Baumgarten M, Siemiatycki J, Gibbs GW. Validity of work histories obtained by interview for epidemiologic purposes. Am J Epidemiol 1983;118:583-91.

14. Coggon D, Pippard EC, Acheson ED. Accuracy of occupational histories obtained from wives. $\mathrm{Br} \mathrm{J}$ Ind Med 1985;42:563-4.

15. Herrmann N. Retrospective information from questionnaires: 1 . Comparability of primary respondents and their next-of-kin. Am J Epidemiol 1985;121:937—47.

16. Kolonel LN, Hirohata T, Nomura AMY. Adequacy of survey data collected from substitute respondents. Am J Epidemiol 1977;106:476-84.

17. McLaughlin K, Dietz MS, Mehl ES, Blot WJ. Reliability of surrogate information on cigarette smoking by type of informant. Am J Epidemiol 1987;126:144-6.

18. Pershagen $\mathrm{G}$, Axelson $\mathrm{O}$. A validation of questionnaire information on occupational exposure and smoking. Scand J Work Environ Health 1982;8:24--8.

19. Shalat SL, Christiani DC, Baker EL Jr. Accuracy of work history obtained from a spouse. Scand J Work Environ Health 1987:13:67-9.

20. Lerchen ML, Samet JM. An assessment of the validity of questionnaire responses provided by a surviving spouse. Am J Epidemiol 1986;123:481-9.

21. Pickle LW, Brown LM, Blot WJ. Information available from surrogate respondents in case-control interview studies. Am J Epidemiol 1983;118:99-108.

22. Rogot E, Reid DD. The validity of data from next-of-kin in studies of mortality among migrants. Int $\mathbf{J}$ Epidemiol $1975 ; 4: 51-4$

Received for publication: 9 May 1988 